\title{
The tangible and potential impact of research libraries
}

\author{
Mary Lee Kennedy* \\ Executive Director, Association of Research Libraries, 21 Dupont Circle, Suite 800, Washington, \\ DC 20036, USA
}

\begin{abstract}
This paper presents the Association of Research Libraries (ARL) role as a collaborative partner to positively impact research and learning in a dynamic research enterprise within a society in flux. It highlights the Association's priorities and institutional member practices that advance open scholarship; diversity, equity, and inclusion; and the adoption of outcome and impact research and analyses.
\end{abstract}

Keywords: research libraries, research and learning outcomes, Association of Research Libraries, ARL

\section{Introduction}

This paper is based on the author's presentation at the Annual Meeting of the National Federation of Advanced Information Services on February 13, 2019. It represents the work of the Association of Research Libraries as a collaborative partner in a dynamic research and learning community within a society in flux.

\section{The setting}

Research libraries function in service of the broader missions of higher education, knowledge discovery in all sectors, and civic society. All three arenas are in significant flux in the United States, and to varying degrees around the world. A few brief points suggest the setting.

The value of higher education is being challenged, even when the facts as reported by the American Council on Education demonstrate that college graduates make more money on average and are happier, healthier, and more civically-engaged than those who never completed a degree [1]. These challenges, along with projected shifts in higher education demographics affected by the low birth rate among U.S. millennials, the population shift to the southwest and west, and the drop in international students, increase the focus on impact and accountability within the higher education systems. In Canada, these shifts are not as dramatic, although the loss in international students in the US may be a gain for the Canadian higher education system.

\footnotetext{
*E-mail: mkennedy@arl.org.
} 
Assuming that the focus of the scholarly disciplines is evidenced by the topics covered in their convenings, there are key takeaways for research libraries on the changing nature of knowledge discovery. The recent 2019 annual meetings of the American Council of Learned Societies and of the National Academies of Sciences, Engineering, and Medicine highlighted the emphasis on international collaborations, vast numbers of collaborators over extended periods of time, across disciplines, based on machine learning, data/"big data" science, simulations, and the research expression as rich media research products composed of dynamic sources. Additionally the research shared in these two convenings was fundamentally focused on generating more inclusive human impact for the present state and for thousands of years to come.

More broadly it is said we exist within the "post-truth era" when the value of critical thinking, evidencebased decision-making, and debate are challenged within an acutely polarized society. The convenience of algorithmic-based services, and predictive analytics, along with the fast-developing capabilities of technologies associated with the fourth industrial revolution, move more quickly than our ability to understand, discuss, and appropriately safeguard ethics, let alone legislation and public policy.

\section{The role of the Association of Research Libraries in this context}

In service of our mission

The Association of Research Libraries achieves the 2033 vision through our mission to advance research, learning, and scholarly communication by fostering the open exchange of ideas and expertise, promoting equity and diversity, pursuing advocacy and public policy efforts, forging partnerships, and catalyzing collective efforts.

In February 2019 the Association of Research Libraries Board of Directors approved the 2019-2021 Action Plan (see Fig. 1), with the shared objective of advancing an equitable and enduring research information environment that meets the needs of scholars (researchers, students, independent scholars) now and in the future. To do so, the Association of one hundred and twenty-four research libraries - represented by library leaders in the United States and Canada from academia, the public sector, and national institutions - is focused on the strategic contributions research libraries can make at the intersection of the research and learning community priorities, institutional policy and practice, and public policy.

Alignment with this intersection is critical if we are to collectively have an impact. With a myriad of interdependent and complex issues in our view, the Association of leaders remains focused on those it has the best potential to positively impact. That means we partner with other leaders, locally in the District of Columbia, and internationally, such as through the International Alliance of Research Library Associations. We partner with US national agencies and international governments, research institutions, learned societies, and colleagues in related fields around the globe. Together we can make a difference. No entity can succeed independently.

With scholars (broadly-defined as students, researchers, and teachers) at the center of all we do, over the next two to three years, the Association intends to demonstrate tangible benefits for scholars by:

(1) Advocating for public policies in support of the mission and shared objective

(2) Catalyzing collective efforts to achieve enduring and barrier-free access to information

(3) Creating diverse, equitable, inclusive, and accessible services, collections, and work environments

(4) Providing data and analytics on research library practices, effectiveness, and impact 


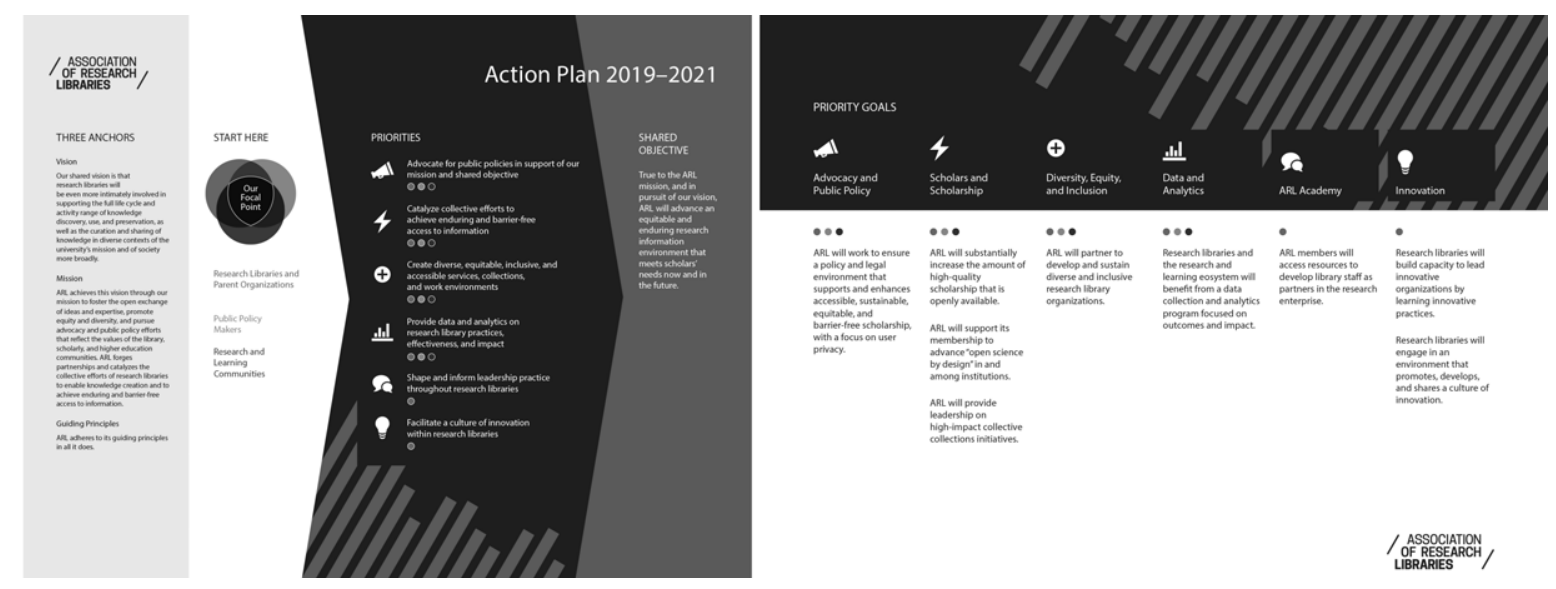

Fig. 1. Association of Research Libraries Action Plan 2019-2021 [2].

In support of the leaders in our member institutions and other research library communities, our priorities aim to shape and inform leadership practice throughout research libraries and to facilitate a culture of innovation within research libraries.

\section{Tangible and potential impacts}

This paper highlights the impact our Association and its members have in three areas (priorities 2-4 noted above) as a result of our efforts to date. Each of these has a direct link with and dependency on engagement in advocacy and public policy.

\subsection{Impact on collective efforts to achieve enduring and barrier-free access to information}

It is only through strategic partnerships that collective efforts will achieve enduring and barrier-free access to information. ARL is partnering with learned societies, U.S. national agencies, and higher education associations to do so. Our member institutions are innovating new practices that inform institutional and public policy, and provide opportunities for other research libraries to leverage what we know in their own context.

\subsubsection{Collective efforts with learned societies}

In December 2018, ARL and the Social Science Research Council convened several learned societies, library publishers, academic librarians, the Association of American Universities (AAU), the Association of Public and Land-grant Universities (APLU), and funders to identify possible projects to advance open scholarship. Five projects were identified and are advancing. The projects include:

(1) An authoritative investigation into scholarly society finances by a trusted third party, as the basis for financial and business model conversations with societies and external stakeholders

(2) A paper on the role of scholarly societies and scholarly affiliation in a post-subscription environment

(3) A case study pilot on linguistics promotion-and-tenure

(4) Exploring implementing peer review in SocArXiv and PsyArXiv

(5) Assessing the impact of the reporting relationship between university presses and university libraries 
With these projects just getting underway, we cannot be certain of the outcomes. However, we are confident that they will inform academy-led scholarly publishing and we look forward to sharing the outcomes with the community.

\subsubsection{Collective efforts with national agencies and higher education associations}

In October 2018, ARL joined a National Science Foundation - funded workshop held by the Association of American Universities and the Association of Public and Land-grant Universities on public access to research data. This is particularly important given the data-centric nature of scholarship and the administrative burden that, among other things, reduces access to research data. The workshop was attended by thirty intact teams of vice presidents of research, chief information officers, general counsels, provosts, academic computing professionals, and librarians, from across the United States and Canada, including eighteen ARL member institutions. This and ongoing collaboration between ARL, AAU, and APLU are informing research library practice and institutional and public policy.

As a means to advancing "open science by design" within member institutions, ARL is working on a road map to implementing FAIR (findable, accessible, interoperable, reusable) principles for complex, digital, scholarly assets. The Association is also working on the collection and dissemination of proven research data management (RDM) policies and practices in order to promote interoperability of shareable assets and the retention of academic control (and ownership) of data products and sharing. Also under development are talking points, policy documents, and strategies for campus administrators around institutional policies for data governance, use and reuse, and stewardship, and a framework for service provision for library operations in the area of RDM. Since data is the unit of analysis for most research today, it is critical to make it feasible to access the data that is valued over time through barrier-free mechanisms.

\subsubsection{Example of ARL member impact: National Library of Medicine's associated data box}

The National Library of Medicine aims to support the discoverability of data underlying publications in PubMed Central. Through the Associated Data Box (see Fig. 2) the library is able to link various forms of information and while adhering to research data policy. The Data Box exposes data-relevant content that is produced and used around the world. This is particularly complicated given the dynamic nature of data, the challenges in accessing networked data stores, and the associated costs in providing access over time.

\subsection{Impact on diversity, equity, inclusion, and accessibility}

More than eighteen years ago a group of ARL member representatives created a fund that established the ARL Initiative to Recruit a Diverse Workforce (now known as the Kaleidoscope Program). Since 2003 this program and others, such as the ARL/Society of American Archivists Mosaic Program and the Fellowship for Digital and Inclusive Excellence, have been attended by more than six hundred fellows with a goal of recruiting under-represented populations to our profession.

Recruitment plays a critical step in creating a diverse workforce. Nevertheless, we have a long way to go to creating an inclusive, equitable, and accessible work environment. Given that, ARL is focused on the development and maintenance of diverse and inclusive organizations and climates by (1) developing 

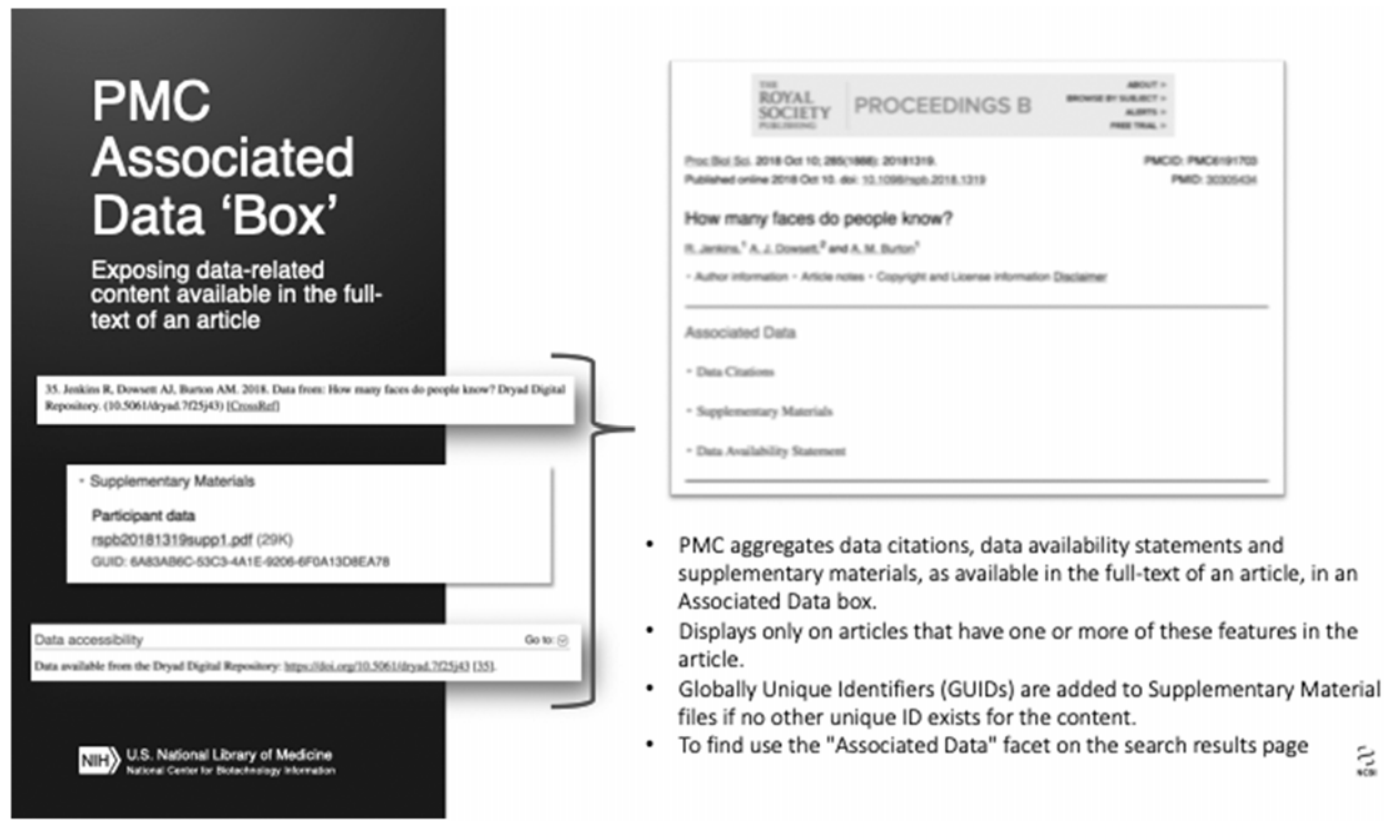

Fig. 2. PubMed Central Associated Data Box. Shared with permission of the National Library of Medicine.

and fostering deeper understanding of the systemic barriers to retention of people from historically under-represented or marginalized populations in the research library and archives workforce and in the profession, and (2) exploring the implications for information and representational equity as it relates to core functional areas of our practice, for example, scholarly communication and publishing, description and metadata, collections, teaching (instruction), accessibility. Our focus remains on recruitment and, more directly, retention and opportunity within institutions by increasing the leadership capacity to create diverse, equitable, and inclusive environments, collections, and services.

\subsubsection{Collective efforts with research libraries and other associations}

The IDEAL Conference scheduled for August 2019 carries forward a successful National Diversity in Libraries conference held in 2016. The IDEAL Conference aims to foster:

- Awareness and appreciation of workplace diversity issues through the exploration of exemplary practice;

- Contemporary theory;

- Thought leadership; and

- Strategy development for all those in the academic and public library, archives, and museum sectors.

In conjunction with the IDEAL conference, ARL member institutions will engage in a full-day workshop on creating an inclusive work environment. This builds on and informs our initiative to address competencies outlined in our forthcoming strategic framework for diversity, equity, and inclusion, as well as the persistent challenges to navigating through careers in libraries and archives for individuals from marginalized or historically under-represented backgrounds. These programs will focus on knowledge and competencies needed at all levels of an organization, including directors, and will be developed in 
collaboration with other library and higher education associations given that it will take all of us to create the needed structural and cultural changes.

\subsubsection{Collective impact on the open web}

On April 18, 2019, the Association of Research Libraries and Wikidata published a white paper by their Joint Task Force [3]. The task force stemmed from an IFLA (International Federation of Library Associations and Institutions) summit that surfaced the following areas of interest:

(1) Using linked open data (LOD) to describe and connect resources, on order to mutually enrich Wikimedia and library discovery sources

(2) Establishing learning communities for Wikimedians in libraries, cultural heritage, and research institutions

(3) Addressing the gaps in content and the cultural barriers inherent in Wikipedia, and conversely, using Wikimedia projects to help address cultural barriers in traditional library and archival practice

The Task Force's recommendations include practical guidance regarding linked open data and a focus on engaging scholars and communities working in underrepresented knowledge areas to help extend existing sets of knowledge in Wikidata. While it isn't clear yet how broadly the recommendations will be adopted by individual librarians or library leaders and organizations, the opportunity to do so in consultation with a connected community of experts now exists.

\subsubsection{Example of ARL member impact: $\underline{X}$ wi7 $\underline{x}$ wa Library at the University of British Columbia}

The Xwi7xwa (which in Squamish means "echo") Library is the only Aboriginal branch of an academic library in Canada. The building's unique architecture represents an interior Salish pit-house (see Fig. 3).

Xwi7xwa librarians and staff are familiar with Indigenous scholarship and community research interests. Annually, the librarians produce a list of courses with significant Indigenous content. For winter session 2018-2019, there are one hundred and eighteen courses, from thirty five different departments. The Xwi7 $\underline{x}$ wa Library collects materials written from Indigenous perspectives, such as materials produced by Indigenous peoples, Indigenous organizations, tribal councils, schools, publishers, researchers, writers, scholars, filmmakers, and musicians. The collections are "tagged" with a corporate name added entry, "X Xwi7xwa Collection," assuring the integrity of the collection as a whole and as being a unique and curated body of knowledge.

\subsection{Collective impact on research library practices, effectiveness, and impact through data and analytics}

Today, research libraries, among all members of the research enterprise, are held accountable for demonstrable impact on research and learning. A role of the Association is to provide the means for institutional members to demonstrate that impact, and to reflect the collectivity of research library impact on the research and learning ecosystem.

In December 2017, the Visioning Task Force issued its recommendations on ARL assessment programs with a goal of developing a forward-looking program that advances the organizational outcomes of the 21st-century research library [4]. One specific result is the development of an organic and modular Research Library Impact Framework focused on research and learning outcomes. Specifically, the framework focuses on services and operations as well as alignment with institutional missions and goals across four critical areas: 


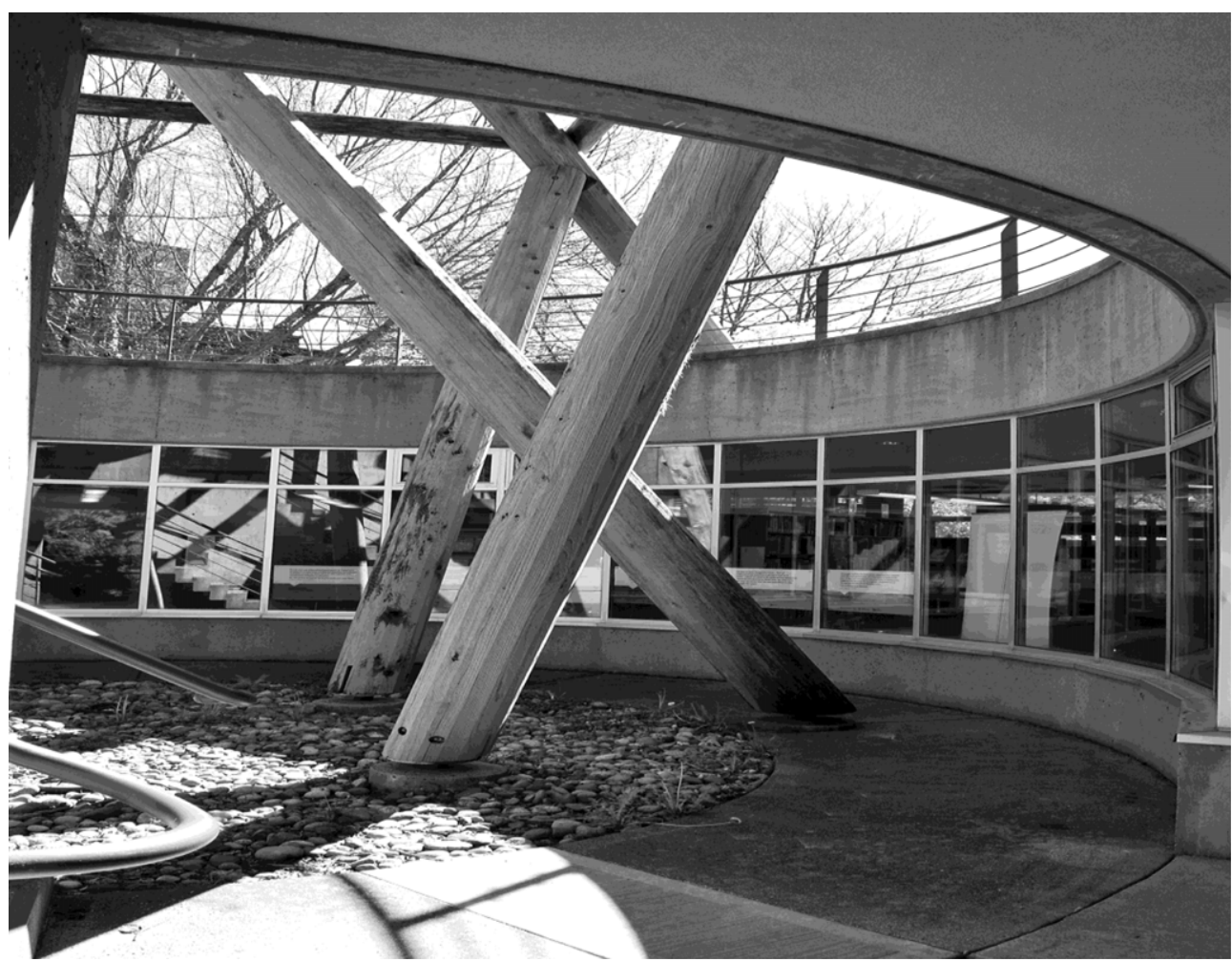

Fig. 3. X Xwi7 $\underline{x}$ wa Library. Shared with permission of the University of British Columbia.

- Research and Scholarly Life Cycle

- Teaching, Learning, and Student Success

- Collections

- Physical Space

This movement away from counting inputs and outputs to understanding impact on institutional goals requires a disciplined approach that stands the test of scrutiny by scholarly communities and senior decision-makers. The approach must be agile enough to adapt as the research results inform decisionmakers. And the approach should focus on those areas where the impact is most needed according to key stakeholders; in other words, it is outwardly- focused on strategy first and, as a result, indicates where to direct research library attention inwardly on practices and policies.

\subsubsection{Example of ARL member impact: The University of Washington's DataLab}

In December 2018, the Association of Research Library held a Leadership Symposium, generously sponsored by EBSCO, with Dr. Jevin West as our guest speaker. Dr. West co-leads the DataLab, a nexus for research on data science and analytics at the University of Washington's (UW) iSchool. The DataLab's goal is to "use data for the social good, in an ethical manner that can inform policy and impact lives for the better" [4]. What is particularly exciting about this is the evidence-based approach that prepares a new generation of information scientists for a data-driven research and learning ecosystem. It also provides 
an opportunity to learn from the "science of science" focus - which ultimately contributes in meaningful ways to understanding and then acting on the impact of institutional and public policy.

\section{Conclusion}

In the intersection of institution policy and practice, research and learning communities priorities, and public policy there are real opportunities for ARL, and research libraries more broadly, to contribute to the advancement of research and learning. I've mentioned some of them here: through collective efforts to achieve enduring and barrier-free access to information; collective efforts to create diverse, equitable, inclusive, and accessible services, collections, and work environments; and in providing outcome- and impact-based data and analytics. There should be no doubt that research libraries are delivering real impact to advance research and learning in academia, research institutions, and civic society.

\section{About the Author}

Mary Lee Kennedy was appointed executive director of the Association of Research Libraries (ARL), effective April 1, 2018. She leads the development and implementation of ARL's strategic direction. She builds on ARL's strengths as a leader and partner in the research and learning ecosystem, as a catalyzer of global opportunity and value through its suite of programs and initiatives, and as a culture that embraces innovation, diversity, and inclusion.

Prior to coming to ARL, Mary Lee was principal of the Kennedy Group, where she partnered with organizations to empower local and global communities to create and use knowledge that enhances lives. She has a wealth of experience in academic research libraries and knowledge corporations, most recently at New York Public Library (NYPL), where she held the position of chief library officer (2013-2016). Before going to NYPL, she served at Harvard University as senior associate provost for the Harvard Library (2011-2013) and executive director of Knowledge and Library Services, Harvard Business School (20042011). Prior to her roles at Harvard, she was director of the Knowledge Network Group at Microsoft (1998-2004).

Mary Lee earned her BA in social psychology and classics at University of Alberta and her master of library science at Louisiana State University. She has lived in Canada, the US, and Mexico; is bilingual in English and Spanish; and has a working knowledge of French. Email Address: mkennedy@arl.org.

\section{References}

[1] There's still time to register for ACE West Summer Summit on demonstrating higher education's value [webpage on the Internet]. American Council on Education (ACE). Washington, DC: ACE; 2019 [updated 2019 May 6; cited 2019 May 14]. Available from: https://www.acenet.edu/news-room/Pages/ACE-Summit-on-Demonstrating-the-Value-of-HigherEducation-by-Meeting-the-Needs-of-All-Students.aspx. Accessed June 16, 2019.

[2] See also: https://www.arl.org/wp-content/uploads/2019/05/arl-prioritization-infgrphc-2019-ecosystem-focused.pdf, Accessed June 16, 2019.

[3] ARL Task Force on Wikimedia and Linked Open Data. ARL white paper on Wikidata: Opportunities and recommendations. Washington, DC: Association of Research Libraries and Wikidata, April 18, 2019. Available from: https://www.arl.org/wpcontent/uploads/2019/04/2019.04.18-ARL-white-paper-on-Wikidata.pdf. Accessed June 16, 2019. 
[4] Assessment Program Visioning Task Force and Athenaeum21 Consulting. ARL Assessment Program Visioning Task Force recommendations. Washington, DC: Association of Research Libraries, December 4, 2017. Available from: https://www.arl.org/wp-content/uploads/2017/12/2017.12.04-AVTF-PublicReport.pdf, Accessed June 16, 2019.

[5] University of Washington Information School DataLab [homepage on the Internet]. Seattle: The University; 2019 [cited 2019 May 14]. Available from: https://datalab.ischool.uw.edu/. Accessed June 16, 2016. 